\title{
Improving mental health systems in Africa
}

The content is based on an article which was prepared for the Commonwealth Health Ministers Meeting held in Geneva Switzerland in May 2013 and is reproduced by kind permission of Nexus Partnerships. This article first appeared in Robertson, A. (ed) Commonwealth Health Partnerships 2013. Cambridge: Nexus/Commonwealth Secretariat. http://www.commonwealthhealth.org/ebook/ CHPl3ebook/\#/l/

\section{Introduction}

Africa is a vast and diverse continent. The diversity relates not only to geography but also languages, cultures, religions and histories. However, conflict, disease, poverty and political instability are common characteristics. Notwithstanding commonalities, to pronounce on Africa in general is problematic. To comment on mental health systems in Africa, and how to strengthen them - one needs an understanding of weaknesses. Again, to presume that one can pronounce on Africa as a continent may indeed be presumptuous. That having been said, the content which follows will provide, at worst, points of departure for discussion and debate - with the intention of identifying a way forward for a continent without losing sight of country specific issues.

\section{Resources}

Critical to adequate service delivery are resources. Clearly any government has limitations on the extent of resources that can be provided for health care. There are a multitude of competing areas that require adequate resources e.g. education, safety and security, justice, public transport, infrastructure, social services etc. Clearly, each country requires a rational hierarchy of needs where for example equipping a country for war when there is no conceivable threat to sovereignty at the expense of other areas of need is clearly illogical, and yet within the context of Africa - not unheard of. The range of resources required encompasses both physical infrastructure and personnel amongst others.

\section{Physical infrastructure}

Psychiatry specific facilities are necessary, recognizing the unique requirements of psychiatric patients whereby coopted medical wards in hospital settings are simply not adequate; further, the need for specialist psychiatric hospitals is not about incarceration but about providing an environment that is focused and appropriate for the treatment of psychiatric patients. Neither of the aforementioned types of inpatient facility negates the requirement of community based services. Likewise, in seeking to manage psychiatric patients as close to their homes as possible through effective community services does not negate, diminish or compensate for in- patient care - which is indeed care in a therapeutic setting.

\section{Personnel}

- Retention

Personnel is obviously a critical resource. Aside from training inadequate numbers of staff is the commonly encountered issue related to loss of trained specialists and medical graduates to developed countries. There are both "push" and "pull" factors. Most medical graduates who work in the state sector are acutely aware of the limitations that exist. Given their commitment to patient care they develop ways of working as best they can within such limitations. However, such working conditions are ultimately disheartening, de-motivating and no doubt contribute to disillusionment and movement out of the sector. Whilst appealing to developed countries to desist from recruitment of locally trained developing world personnel, it is incumbent on developing world countries to examine the "push" factors that drive professionals to seek alternatives to careers in their countries of origin. These "push" factors make personnel susceptible to the "pull" factor of apparent stability and better working conditions in developed countries. That being the case, the African diaspora needs to be fully documented and actively engaged in attempting to create networks that will contribute to patient care and service development in their countries of origin. In this way individual practitioners would not be totally lost as a resource.

- Non-specialists/sub-specialists

Regarding non-specialist medical personnel - the active promotion of diplomas in mental health as opposed to specialist fellowships should be a priority. This speaks to the issue of training, and in this regard one should not ignore the other end of the spectrum i.e. the sub-specialist. There are those who question whether developing world settings can afford to devote resources to such training. A simple example puts that argument in perspective, namely the increasingly youthful demographic of developing world populations which speaks to a need for child and adolescent psychiatrists; another example is the impact of HIV-AIDS on the neurological system and the consequent emergence of psychiatric conditions which speaks to the need for neuro-psychiatrists; there are further examples related to forensic psychiatry, old age psychiatry and addiction psychiatry - all subspecialist disciplines in their own right and all relevant to African 
countries. Sub-specialists do not only treat selected patients, but also provide the knowledge and clinical experience that serves to train general psychiatrists.

\section{- Allied professionals}

Clearly medical specialists form the core of psychiatric services but in developing world settings the lack of adequate numbers of specialists emphasizes the need for and requirement of suitably skilled non specialists as well as allied mental health professionals such as nurses, occupational therapists, social workers and psychologists. Of all medical disciplines, Psychiatry is the one that routinely utilizes a multidisciplinary approach and in so doing provides truly holistic treatment to patients and their families. The extent to which allied professionals are understood to be integral to optimal care cannot be overstated and should be a nonnegotiable requirement.

\section{- Task shifting}

In addition, the possibility of "task shifting" needs to be more fully implemented with the appropriate skills acquisition by non-medical health workers. It is not uncommon for services to be predominantly staffed by nurses, with Psychiatry being no exception. Specialist nursing skills are no less important than specialist medical skills. Further, it is not inconceivable that suitably skilled non- health workers and volunteers might be an option for assisting with both de-stigmatization and medication adherence through community based initiatives.

\section{Information technology}

A major concern is the availability of adequate information technology. Appropriate resource provision requires accurate data, in terms of describing services rendered which contributes to defining needs and allocating budget. Fundamentally - what do psychiatric services cost ? Record keeping is critical and encompasses not just informing economic decisions but also has both ethical and legal implications. The possibility of electronic record keeping will allow for more rapid dissemination of patient information between sites, as well as retention of patient information - both of which would contribute to patient care. Whilst the aforementioned relate to institutional requirements, at an individual level the advent of cellular/mobile telephone technology with its rapid uptake in Africa, may offer unique opportunities to enhance patient care e.g. medication compliance.

\section{Medication}

- Access

The advance of medical science, and in the neurosciences specifically, has witnessed a proliferation of medications targeting mental illness. Whilst the primary aim is the relief of symptoms, there is a need to ensure that this is not at the expense of unwanted and potentially toxic side effects - which might harm the patient directly and/or contribute to nonadherence to medication with consequent inadequate response to treatment. Inherent to the aforementioned are two issues, namely - availability of medication and compliance with prescribed medication. Regarding availability, cost is a significant factor which frequently limits access. Whilst developing world populations often contribute to the testing of new drugs, the eventual cost limits subsequent availability for these same populations. Logistical issues related to medication procurement and supply chain management are vital components of service delivery i.e. ensuring that what is indeed purchased actually reaches the intended sites.

\section{- Adherence}

Adherence to medication is a perennial issue, and nonadherence frequently contributes to both recurrence of symptoms and relapse of condition. Ensuring adherence is a multifaceted problem, with psycho-education targeting both patients and their support systems being integral to successful treatment. Allocation of resources needs to be cognizant of such requirements, specifically in terms of both training and availability of staff to deliver this component of an intervention.

\section{Stigma}

- Individual

Most health professionals would instinctively view stigma as a phenomenon affecting individual patients with mental illness who by virtue of their illness experience isolation, rejection or discrimination within broader society. Whilst much effort is devoted to inclusion and attempting to convince those without mental illness to have a non-discriminatory understanding of those who do have mental illness, to date this remains an ongoing pursuit notwithstanding efforts to legislate such attitudes (not least of all in the work domain).

\section{- Institutional}

Beyond the individual, there is much work to be undertaken at an institutional level - to confront institutional stigma. Such stigma is quite possibly more iniquitous in that it sees Psychiatry as a discipline dismissed by fellow professionals and underfunded by government. The approach to confronting such stigma would appear to require professionals who are adequately equipped to effectively motivate for change, not only through direct engagement with government individually and through representative bodies but by linking with NGOs. Two related areas warrant mention i.e. undergraduate and medical internship training.

\section{- Training}

There is a need to ensure that adequate and appropriate exposure to psychiatric patients occurs, together with didactic teaching. The curricula of undergraduate medical studies should reflect the importance of mental health as a component of health, which by implication requires not just the promotion of mental health but the treatment of mental illness. Given the increasing burden of mental illness, it is incumbent on medical graduates to have adequate knowledge and skills, which should be further consolidated through dedicated rotations through psychiatric units during their internship years, leading to independent practice as medical practitioners or further training as specialists.

\section{Integration}

The concept of integration operates at two levels, that of the patient into their community and that of the patient into the health system. Regarding the former, developed countries around the world have actively promoted a policy of deinstitutionalization with a reduction in both chronic and 
acute psychiatric beds. The aim was to achieve a return to the community of psychiatric patients. As laudable as these efforts may have been, it is not clear that such an approach has yielded the desired outcome, not least of all where beds have been reduced but adequate resources have not been allocated for the support and development of community services. In such a situation, the services suffer a double blow. There needs to be a balance, which can most likely be achieved with a truly holistic view of patient needs through the course of illness which ranges from hospitalization (acute/longer stay) to community based care. Whilst there is a need for specialist community services, it is likely that many psychiatric patients could be managed in the primary care setting by non-specialists provided they are adequately trained and supported. Inherent to the aforementioned is the need to carefully plan for a range of services that provide for a patient's needs at the level required.

\section{- Traditional healers}

A final word on "integration" must, within an African context, make mention of traditional healers. There is an increasing awareness that whilst medical models provide for care of the patient's disease (as understood by the medical practitioner), one needs to be aware of the patient's experience of their illness - which may see them consult outside of medical structures. There is a need to integrate this reality into any understanding of what constitutes the package of care, and to actively engage to ensure optimal intervention.

\section{Legislation}

Mental health legislation exists in many African countries. The aim should be to ensure that all African countries have the appropriate legislation as part of a continent wide move to provide for a most vulnerable section of the population. Whilst such legislation speaks to the unique circumstances of those suffering with a mental illness, legislation is meaningless without appropriate resources to both implement and monitor

\section{Advocacy}

Part of medical professionalism involves advocacy which, in short, places an obligation on health professionals to actively engage with decision makers in motivating for the provision of adequate patient care. Medical professionals need to be suitably skilled in the art of negotiating a better deal for the patients they serve. Such interaction should however not be an individual pursuit, but should involve collective approaches that are channelled through representative bodies of health professionals. The realm of advocacy is often pursued by nongovernmental organizations (NGOs), who without fear of recrimination and often with greater resources than individual medical staff or professional organizations can actively engage with government, with focus. The Treatment Action Campaign in South Africa that forced the government through the country's constitutional court to ensure availability of anti retro viral drugs for human immunodeficiency virus (HIV) infected sufferers of acquired immunodeficiency disease (AIDs) is an illustration of a successful action of this nature. important that beyond having zonal WPA representatives in Africa, that as a continent there is a representative body that provides active support to professional bodies within individual African countries as well as assists them in promoting African issues beyond WPA structures. The African Association of Psychiatrists and Allied Professionals (AAPAP) is such an organization, however it is no small task to create a critical level of momentum and credibility that would enable such an association to play the role it should and can play. Through the African Journal of Psychiatry, in existence since August 2007 www.ajop.co.za, the promotion of African research has provided not just a platform for African psychiatrists to convey research that is locally relevant but has also provided a window for international psychiatrists into African psychiatry that may indeed inform their practice. A recent - 2011 - publication Contemporary Psychiatry in Africa: A Review of Theory, Practice and Research (Acrodile Publishing Limited - www.acrodile.co.ke) brought together a collection of African psychiatrists in writing chapters that provided a status quo of African psychiatry on a range of conditions and issues, which together with peer review from psychiatrists outside of Africa created a truly international collaborative effort. The development of African researchers and the creation of indigenous knowledge is critical to informing local practice and developing services that are appropriate for Africa.

\section{Conclusion}

The issues raised are not exhaustive. Additional areas of focus could have included the physical i.e. non psychiatric medical requirements of psychiatric patients, more detail on substance abuse, as well as factors which contribute to mental illness such as the family, societal change, bullying in schools, urbanization etc. Notwithstanding such omissions, the content highlights a range of issues and provides some insight into their relevance - each topic could easily be the subject of further and more detailed discussion. However, the aim has been to highlight one specific point - in pursuit of better psychiatric and related services in Africa there are many aspects to consider, and that such consideration must adopt an inclusive approach incorporating the multitude of factors. Herein lies the challenge.

Living in Africa one is familiar with news of political leaders leaving their countries of origin to receive medical care. Status confers opportunity; status allows for inequality. Politicians serve - in democracies where government and officials are held accountable. Where there is leadership that leads by example, and exists without privilege - change will surely follow. A concrete illustration of such an ethos involves something as straightforward as encouraging politicians and elected officials to use the state medical system for themselves and their dependents. What is good for the common citizen should be adequate for those elected by them to serve. When the politician's medical care of choice is state funded - they will surely ensure that such care is adequately funded by the state. This is where change begins, with leadership.

\section{Common purpose}

Christopher Paul Szabo

Whilst internationally the discipline of Psychiatry is well served by the World Psychiatric Association (WPA), it is 